\title{
Mesleki Eğitimde Ders Çalışma Yaklaşımlarının Belirlenmesi
}

\author{
Mesut ÖZONUR, Halil KAMIŞLI*
}

\begin{tabular}{ll}
\hline $\begin{array}{l}\text { Mesleki Eğitimde Ders Çalışma Yaklaşımlarının Belir- } \\
\text { lenmesi }\end{array}$ & $\begin{array}{l}\text { Determination of Study Approaches in Vocational } \\
\text { Education }\end{array}$ \\
\cline { 1 - 2 } Özet & Abstract
\end{tabular}

Araştırma, önlisans düzeyinde üniversite öğrencilerinin ders çalışma yaklaşımlarının nasıl olduğu ve akademik başarı ile arasındaki ilişkiyi belirlemeye yönelik tarama modeli biçiminde desenlenmiştir. Araştırmanın katılımcılarını Çukurova Üniversitesi Adana Meslek Yüksekokulu öğrencileri ( $\mathrm{N}=651$ ) oluşturmaktadır. Araştırmada veri toplamak amacıyla, Yılmaz ve Orhan tarafından Türkçe'ye uyarlanan "Ders Çalışma Yaklaşımı Ölçeği” kullanılmıştır. Ölçek, "yüzeysel yaklaşım" (10 madde) ve "derin yaklaşım" (10 madde) olmak üzere iki faktörden oluşmaktadır. Verilerin analizinde Ki-Kare ve Cramer's V istatistiklerinden yararlanılmıştır. Araştırma sonucunda ders çalışma yaklaşımları ile akademik başarıları arasında anlamlı bir ilişki bulunmuştur. Ders çalışma sürecinde derin yaklaşımı benimseyen öğrencilerin akademik başarılarının daha yüksek olduğu sonucu elde edilmiştir. Öğrenmeyi ve akademik başarıyı etkileyen diğer faktörler ile ilgili de çalışmaların yapılması önerilmektedir.

Anahtar Kelimeler: Ders Çalışma Yaklaşımları, Derin Ve Yüzeysel Yaklaşım, Mesleki Eğitim, Akademik Başarı.
The study was designed as a survey model to determine the relationship between academic achievement and the students' study approach of university students at the associate level. The participants of the study are the students of Çukurova University Adana Vocational School of Higher Education ( $N=651$ ). In order to collect data in the study, Course Study Approach Scale adapted by Yılmaz and Orhan to Turkish was used. The scale consists of two factors: the surface approach (10 items) and the deep approach (10 items). Chi-Kare and Cramer's V statistics were used in the analysis of the data. As a result of the study, a significant difference was found between course study approaches and academic achievement. In the course study process, it was concluded that the students who adopted the deep approach had higher academic achievement. It is recommended that studies should be carried out on other factors affecting learning and academic achievement.

Key Words: Study Approaches, Deep and Surface Approach, Vocational Education, Academic Achievement.

\section{Giriş}

Son yüzyılda giderek artan küresel rekabet karşısında ülkelerin başarılı olma ve gelişmiş ülkeler sınıfında bulunma isteği, toplumların ihtiyaç duyduğu birey özelliklerini yeniden tanımlanmasına neden olmuştur. Küreselleşme ile birlikte bilgiyi hazır alan insan tipi değişmiş ve bilgiye ulaşan ve bilgiyi kullanan insan tipi ön plana çıkmıştır. Sınırların

"Mesut ÖZONUR, Dr., Çukurova Üniversitesi, ozonur@cu.edu.tr, ORCID ID: orcid.org/0000-0002-7930-9478, Halil KAMIŞLI, Dr., Uluslararası Final Üniversitesi, halil.kamisli@final.edu.tr, ORCID ID: orcid.org/0000-0001-6715-431X 
Mesut ÖZONUR | Halil KAMIŞLI

kalkması ve teknolojinin gelişmesi ile beraber bilgiye ulaşmak kolaylaşmıştır. Artık önemli olan bilgiye sahip olmak değil, bilginin beceriye dönüştürülmesi olmuştur. Gelişmiş toplumlarda araştıran, yorumlayan ve sorun çözen bireylere ihtiyaç duyulmaktadır. Bu özelliklere sahip bireylerin yetiştirilmesi için eğitim programlarının her boyutunda bu amaca hizmet edecek yeniliklere ihtiyaç vardır. Yirmi yıl sonra günümüz mesleklerinin birçoğunun olmayacağı konuşulurken, mesleki eğitim süreçlerinin de bu değişimler çercevesinde revize edilmesi gerekli görülmektedir. Çünkü artık mesleklere yönelik sadece konu merkezli eğitimler yerine, mesleki alan eğitimini de içinde barındıran aynı zamanda da yukarıda değinilen birey özelliklerinin kazandırıldığı bir eğitim sürecine ihtiyaç vardır.

Alkan, Doğan ve Sezgin (1991), mesleki eğitimi, bireye iş hayatında belirli bir meslekle ilgili bilgi, beceri ve iş alışkanlıkları kazandıran ve bireyin yeteneklerini çeşitli yönleriyle geliştiren eğitim olarak tanımlamaktadırlar (s.6). Küresel rekabette ülke adına başarılı olma amacı ile mesleki eğitim veren tüm kurumlarda kayıtlı olan öğrencilerin istenen bilgi ve becerilerine sahip olarak mezun edilmesi gerekmektedir. Bu durumun gerçekleşmesi mesleki eğitim programlarının hedeflerinin başarı ile gerçekleşmesine bağlıdır. Eğitimde başarı, ders sürecinde öğrencilerin değerlendirilmesi ile verilen notlarla, sınav puanları ile veya her ikisiyle beraber belirlenen beceriler veya kazanılan bilgilerin ifadesi olan "akademik başarı" kavramı ile ifade edilmektedir. Akademik başarı öğrencilerin mesleki ve sosyal hayata uygun olarak hazırlanmalarını gerçekleştirdiği ve geleceklerine şekil verdiği için, ebeveynleri çevreleri bakımından da oldukça önemli görülmektedir (Sarıer, 2016). Eğitim sürecinde akademik başarıyı etkileyen birçok değişkenin (zeka, öğrenme hızı vb. zihinsel faktörler, öz-yeterlik, benlik saygısı, kişilik yapısı, motivasyon ve ders çalışma alışkanlıkları, ailenin sosyo-ekonomik durumu, anne-baba tutumu, okul yöneticilerinin ve öğretmenlerin yeterliliği ve tutumu gibi) olduğu bilinmektedir. Bu değişkenlerin akademik başarıyı etkilediğini gösteren çok sayıda araştırma yapılmıştır (Arıcı, 2007; Dağdelen, 2013; Howie ve Pieterson, 2001; Özer ve Anıl, 2011; Polat, 2009; Şevik, 2014; Wang, 2004;). Bu değişkenlerden biri olan ders çalışma yaklaşımı, içerisinde not tutma, tekrar stratejileri, düzenli sınav hazırlıkları, ders kaynaklarından yararlanma ve problem çözme becerileri ile ilgili çalışma tekniklerini barındıran, düzenli ve sistemli çalışma olarak tanımlanabilir (Demircioğlu Memiş, 2007; Purdue ve Hattie, 1999; Wagner, Schober ve Spiel, 2008). Ders çalışma yaklaşımları ile ilgili yapılan ilk çalışmalardan biri Brown ve Holtzman (1966) tarafından yapılmıştır. Bu araştırmada başarılı bir ders çalışma yaklaşımı için dört faktör belirlenmiştir. Bu faktörler (1966; akt. Entwistle ve McCune, 2004);

1. Etkili ders çalışma süreci

2. Verilen görev/ödevi tamamlamada hız

3. Öğretmen hakkında olumlu görüş

4. Dersin hedeflerini benimseme

Ders çalışma yaklaşımları ile ilgili yapılan birçok araştırmada, ders çalışma yaklaşımlarının öğrencilerin akademik başarılarını etkilediği yönünde sonuçlara 
ulaşılmıştır (Bonsaksen ve diğ., 2017; Hassanbeigi ve diğ., 2011; Jansen ve Suhre 2010; Özer ve Anıl, 2011; Patterson ve diğ., 2003; West ve Sadoski 2011). Bu çalışmalarda özellikle ders çalışma yaklaşımının önemine vurgu yapılmıştır. Farklı olarak Rostaminezhad, Porshafei ve Ahamdi (2019) yaptıkları çalışmada ise, sosyal ağların ders çalışma yaklaşımlarını dolayısı ile akademik performansı etkilediğini ortaya koymuşlardır.

$\mathrm{Bu}$ alanda yapılan diğer bir araştırma, ders çalışma sürecindeki öğrenci amaçlarına odaklanmıştır. Bu araştırma da vurgu yapılan durum; ders çalışma sürecinde bazı öğrencilerin konuyu tam olarak anlamak amacıyla yola çıkarlarken, diğerlerinin ise sadece ders geçme amacı ile öğrenme etkinliğinde bulunmalarıdır (Biggs, 1999).

Marton ve Säljö (1976) tarafından yapılan araştırma da ise bir grup üniversite öğrencisi ile çalışıımış ve öğrencilerin nasıl ders çalıştıklarına ilişkin derin veya yüzeysel olmak üzere iki ayrı düzey belirlenmiştir. Çalışma sonunda; derin düzeyde ders çalışan öğrencilerin öğrenme ile ilgili çabaları okuduğunu anlama amacı ile ilişkilendirilirken yüzeysel düzeyde ders çalışan öğrencilerin sadece sınav esnasında yeterli notu almayı hedeflediklerine vurgu yapılmıştır (1976; akt. Yılmaz ve Orhan, 2011).

Alanyazında öğrencilerin öğrenme etkinliği sırasında derin ya da yüzeysel yaklaşımlardan bir tanesine göre davrandığı yönünde görüşler mevcuttur. Derin yaklaşım kullanan öğrencilerin öncelikli hedefleri yüksek not almak değil, konuyu anlayarak içselleştirmektir. $\mathrm{Bu}$ maksatla kendilerine sunulan konuyu sorgular, araştırır ve günlük hayat ile ilişkisini kurarlar. Yüzeysel yaklaşımı içselleştiren öğrenciler ise değerlendirme sürecine odaklanıp kendilerinden beklenen minumum başarıyı göstermeye çalışırlar. Bu maksatla konunun bütününe odaklanmayıp, parçalar halinde ezbere yönlenirler. (Beattie, Collins ve Mclnnes, 1997; Biggs, 1999; Entwistle, 2000; Ramsden, 1991). Derin ve yüzeysel yaklaşım özelliklerinin daha iyi anlaşılması adına Tablo 1'de karşılaştırmalar verilmiştir (Houghton, 2004).

Tablo 1. Derin ve Yüzeysel Yaklaşım Özelliklerinin Karşılaştırması

\begin{tabular}{|c|c|c|}
\hline & Derin Yaklaşım & Yüzeysel Yaklaşım \\
\hline Tanım & $\begin{array}{l}\text { Yeni olguları ve fikirleri eleştirel bir } \\
\text { gözle incelemek, mevcut bilişsel yapı- } \\
\text { lara bağlamak ve fikirler arasında sayı- } \\
\text { sız bağlantı kurmak. }\end{array}$ & $\begin{array}{l}\text { Yeni gerçekleri ve fikirleri eleştirel } \\
\text { olarak kabul etmek ve bunları izole, } \\
\text { bağlantısız, öğeler olarak saklamak }\end{array}$ \\
\hline Özellikler & $\begin{array}{l}\text { - Anlam arama } \\
\text { - Bir problemi çözmek için gereken } \\
\text { ana argüman veya kavramlara } \\
\text { odaklanma } \\
\text { - Aktif olarak etkileşime girme } \\
\text { - Farklı modüller arasında bağlantı } \\
\text { yapma }\end{array}$ & $\begin{array}{l}\text { - Ezberci öğrenme } \\
\text { - Bilgiyi pasif olarak almak } \\
\text { - ilkeleri örneklerden ayırt } \\
\text { edememek } \\
\text { - Yeni bilgiyi önceki bilgilerin üzerine } \\
\text { inşa etme ihtiyacı duymama } \\
\text { - Ders içeriğini sınavda öğrenilecek }\end{array}$ \\
\hline
\end{tabular}


Mesut ÖZONUR | Halil KAMIŞLI

\begin{tabular}{llll}
\hline & \multicolumn{2}{c}{ - Yeni ve önceki bilgileri ilişkilendirme } & materyal olarak görmek. \\
& - Ders içeriğini gerçek hayatla & \\
& ilişkilendirme & & \\
\hline Teşvik etme & - Konuyla ilgili olarak gerçekten & - ilgi duyduğu için değil sınıf geçmek \\
(Öğrenci) & meraklı olmak & & için çalışma \\
& - Akademik çalışma yaparken iyi & - Akademik alanlara odaklanmaktan \\
& yapmaya zihinsel olarak kararlı & çok başka alanlara odaklı \\
& olmak & - Konuyu anlamak için gerekli bilgi \\
& - Sağlam bir temel için uygun geçmiş & ve anlama eksikliği \\
& bilgisine sahip olmak & - Yetersiz zaman / Çok yüksek iş \\
& - Iyi zaman yönetimi ile ilgi alanlara & yükü \\
& yönelik ilgisini sürekli tutmak & - Çok fazla endişe \\
\hline
\end{tabular}

Küresel değişmeler ve rekabetin artması ile tekrar şekillenen ve birey özelliklerinin (bilgiyi hazır alan değil, bilgiye ulaşan ve bilgiyi kullanan, bilgiye sahip olan değil, bilgiyi beceriye dönüştürebilen insan tipi) mesleki eğitim sürecinde de hedef olarak alınması ve öğrencilerin bu yönde bilgi ve beceri ile donatılması gereklidir. Bu hedeflerin gerçekleşmesinde, derin yaklaşım stratejilerinin öğrenciler tarafından benimsenmesinin önemli olduğu düşünülmektedir. Çünkü bu yaklaşımı benimseyen öğrencilerin öğrenme sürecinde sergilediği yaklaşımlar, küresel değişimin istediği ve yeniden tanımladığı birey özelliklerine uymaktadır ve günümüz şartlarında bu öğrencilerin yüzeysel yaklaşımını benimseyen öğrencilerden daha başarılı olmaları ihtimali daha yüksektir. Nitekim yapılan araştırmalarda derin yaklaşımı benimseyen öğrencilerin diğer öğrencilere göre daha başarılı olduğu bulunmuştur (Booth, Luckett ve Mladenovic, 1999; Byrne, Flood ve Willis, 2002; Gow, Kember ve Cooper, 1994). Ayrıca Miškulin ve Vrdoljak (2017) yaptıkları çalışmada akademik başarı ile derin öğrenme yaklaşımı arasında pozitif, yüzeysel öğrenme yaklaşımı arasında negatif bir ilişki olduğu sonucunu elde etmişlerdir. Bu açıdan düşünüldüğünde mesleki eğitim sürecinde belirlenen hedeflere ulaşmak adına öğrencilerin başarılarını tayin eden değişkenlerden biri olan ders çalışma yaklaşımlarını belirlemek önemli hale gelmektedir. Bu belirleme süreci sonunda yüzeysel yaklaşımları benimseyen öğrencilerin, derin yaklaşımları benimsemeleri de sağlanabilir. Çünkü öğrencinin benimsediği ders çalışma yaklaşımı, konu ve öğretmeniyle kurduğu ilişki ve derslerin öğretmen ya da öğrenci merkezli işlenmesi ile ilgili olarak değişiklik gösterebilmektedir (Ramsden, 1991; Spencer, 2003).

Bu noktadan hareketle mesleki eğitim sürecinde hedeflenen noktalara ulaşmak için eğitimcilerin, öğrenci merkezli ve etkileşimli öğretim ortamları sunmaları, ayrıca ders ortamında var olan yüzeysel yaklaşıma sahip öğrencileri belirleyerek bu öğrencilerin derin yaklaşım kapsamındaki stratejileri kullanmaları yönünde önlemler almaları çok önemli görülmektedir. Bu amaçla yapılan çalışmada; önlisans düzeyinde üniversiteye kayıtlı öğ- 
rencilerin ders çalışma yaklaşımları ile akademik başarıları arasındaki ilişkinin belirlenmesi amaçlanmıştır ve bu amaca yönelik aşağıdaki alt problemlere cevap aranmıştır;

1. Önlisans düzeyinde üniversite öğrencilerinin ders çalışma yaklaşımları nasıldır?

2. Önlisans düzeyinde üniversite öğrencilerinin ders çalışma yaklaşımları ile akademik başarıları arasında bir ilişki var mıdır?

\section{Yöntem}

Araştırmanın yöntemi, önlisans düzeyinde üniversite öğrencilerinin ders çalışma yaklaşımlarının nasıl olduğu ve akademik başarı ile arasındaki ilişkiyi belirlemeye yönelik tarama modeli biçiminde desenlenmiştir. Araştırmanın katılımcılarını Çukurova Üniversitesi Adana Meslek Yüksekokulu öğrencileri oluşturmaktadır. Araştırma kapsamında 651 öğrenciden veriler toplanmıştır. Öğrenciler Bilgisayar Programcılığı, Çocuk Gelişimi, Elektrik, İlimlendirme ve Soğutma Teknolojisi, Elektronik-Haberleşme Teknolojisi, Şarap Üretim Teknolojisi, Radyo ve Televizyon Programcılığı, İnşaat, Makine, Otomotiv, Muhasebe ve Vergi Uygulamaları, Saç Bakımı ve Güzellik Hizmetleri, Turizm ve Seyahat Hizmetleri, Tekstil Teknolojisi, İç Mekan Tasarımı, Moda Tasarımı, Emlak ve Emlak Yönetimi ve Elektronik Teknolojisi programlarında öğrenim görmektedirler. Katılımcıların, ortalama yaşı 21,3 olan, \%40 ( $N=260)^{\prime} ı n ı$ kadın, ortalama yaşı 21,5 olan, \%60 ( $\left.N=391\right)^{\prime}$ ını erkek öğrenciler oluşturmaktadır. Katılımcıların \%43'ü genel lise, \%57'si meslek lisesi mezunu olup \%74'ü sınav ile \%26'sı sınavsız geçiş yolu ile üniversiteye yerleşen öğrencilerden oluşmaktadır.

Araştırmada veri toplamak amacıyla, Yılmaz ve Orhan tarafından Türkçe'ye uyarlanan "Ders Çalışma Yaklaşımı Ölçeği" kullanılmıştır. Ayrıca öğrencilere yönelik demografik bilgilerin elde edilebilmesi için araştırmacılar tarafından oluşturulan bir Kişisel Bilgi Formu'ndan yararlanılmıştır. Ders çalışma yaklaşımı ölçeği, 5'li likert tipte, 20 maddeden oluşmaktadır. Ölçeğin dereceleri "Hiç Geçerli Değil (1)”, "Bazen Geçerli (2)”, "Geçerli (3)”, "Sık Sık Geçerli (4)" ve "Her Zaman Geçerli (5)" olarak yer almaktadır. Ölçek, "yüzeysel yaklaşım" (10 madde) ve "derin yaklaşım" (10 madde) olmak üzere iki faktörden oluşmaktadır. Ölçekten alınan daha yüksek puana göre öğrencilerin öğrenme yaklaşımları belirlenmektedir. Ölçeğin "derin yaklaşım”a ilişkin Cronbach Alfa değeri .84, "yüzeysel yaklaşım"a ilişkin Cronbach Alfa değeri .76 olarak elde edilmiştir.

Toplamda 651 geçerli sayılan "Kişisel Bilgi Formu" ve "Ders Çalışma Yaklaşımı Ölçeği" değerlendirilmiştir. Bu değerlendirme sonucu istatistiki analizlerde kullanılabilecek 623 uygun veri elde edilmiştir. Ölçekteki yüzeysel ve derin yaklaşım faktörleri normal dağılım göstermediği için verilerin analizinde Ki-Kare ve Cramer's $V$ istatistiklerinden yararlanılmıştır. Demografik değişkenlerin sınıflanmasının ardından elde edilen veriler ilgili istatistik yöntemler kullanılarak öğrenme yaklaşımı ile akademik başarı arasındaki ilişkinin boyutu belirlenmiştir. 
Mesut ÖZONUR | Halil KAMIŞLI

\section{Bulgular}

Araştırmada öğrencilerin ders çalışma yaklaşımları ile akademik başarıları arasında ilişki olup olmadığını belirlemek amacıyla Ki-Kare testi ve ilişkinin boyutu belirlemek için Cramer's V testinden yararlanılmıştır. İstatistiksel analiz sonucunda elde edilen bulgulara aşağıdaki tablolarda yer verilmiştir.

Araştırmada öğrencilerin ders çalışma yaklaşımlarına (derin ve yüzeysel) yönelik betimsel değerler elde edilmiştir. İstatistiki analiz sonucunda ulaşılan bulgular Tablo 2'de verilmektedir.

Tablo 2. Betimsel Değerler

\begin{tabular}{lcc}
\hline \hline & $N$ & $\%$ \\
\hline Derin & 304 & 48,8 \\
Yüzeysel & 319 & 51,2 \\
Toplam & 623 & 100 \\
\hline
\end{tabular}

Tablo 2 incelendiğinde öğrencilerin ders çalışma yaklaşımlarından derin yaklaşımı benimseyen öğrenci sayısı 304 (\%48,8) iken yüzeysel yaklaşımı benimseyen $319(\% 51,2)$ olarak elde edilmiştir.

Tablo 3. Ki-Kare Testinde Kullanılan Veri Değerleri

\begin{tabular}{llllllll}
\hline \hline & \multicolumn{3}{c}{ Kullanılan } & \multicolumn{2}{c}{ Geçersiz } & \multicolumn{2}{c}{ Toplam } \\
\cline { 2 - 7 } & $N$ & Yüzde & $N$ & Yüzde & $N$ & Yüzde \\
\hline $\begin{array}{l}\text { Ders Çalışma Yaklaşımları* } \\
\text { Akademik Başarı }\end{array}$ & 623 & 95,7 & 28 & 4,3 & 651 & 100,0 \\
& & & & & & \\
\hline
\end{tabular}

Tablo 3'de araştırmada istatistiksel analizde kullanılan verilere yönelik değerler verilmiştir. Görüldüğü üzere veriler 651 öğrenciden elde edilmesine rağmen 623 geçerli veri bulunmaktadır. Verilerin analizinde 28 verinin ders çalışma yaklaşımları (derin ve yüzeysel) ortalamalarının eşit olduğu görülmüştür. Bu nedenle istatistiksel analizler geçerli ve uygun verilere göre yapılmıştır.

Tablo 4. Ders Çalışma Yaklaşımları ve Akademik Başarılarına Ait Çapraz Tablolama

\begin{tabular}{lcccc}
\hline \hline & Başarısız & Başarılı & Çok Başarılı & Toplam \\
\hline Derin Yaklaşım & 70 & 187 & 47 & 304 \\
Yüzeysel Yaklaşım & 109 & 195 & 15 & 319 \\
Toplam & 179 & 382 & 62 & 623 \\
\hline
\end{tabular}


Tablo 4'de öğrencilerin ders çalışma yaklaşımları ve akademik başarıya yönelik çapraz tablolama yer almaktadır. Görüldüğü üzere derin ve yüzeysel yaklaşımda "başarılı" kategorisinde öğrenci sayıları birbirine çok yakındır. Ancak "başarısız" ve "çok başarılı" kategorisinde ise derin yaklaşım ve yüzeysel yaklaşım değerleri birbirinden çok farklıdır. Bu farklılık "başarısız" kategorisinde yüzeysel yaklaşım yönünde olurken "çok başarılı" kategorisinde derin yaklaşım yönündedir.

Tablo 5. Ki-Kare Testi Sonucu

\begin{tabular}{lccc}
\hline \hline & Değer & $s d$ & $p$ \\
\hline Pearson Ki-Kare & 24,834 & 2 &, 000 \\
\hline
\end{tabular}

Diğer yandan Tablo 5'te öğrencilerin ders çalışma yaklaşımları ile akademik başarıları arasında istatistiki olarak anlamlı bir ilişki olduğu Ki-Kare testi sonucunda ortaya çıkmıştır $(p<.005)$. İlişki olması nedeni ile $2 \times 3$ boyutundaki tablolarda ilişkinin boyutunu belirlemek için Cramer's $V$ testi yapılmıştır.

Tablo 6. Cramer's V Testi Sonucu

\begin{tabular}{lll}
\hline \hline & Değer & $p$ \\
\hline Cramer's V &, 200 &, 000 \\
\hline
\end{tabular}

Tablo 6'da görüldüğü gibi Cramer' V testi sonucu da Ki-Kare gibi anlamlılık göstermektedir $(p<.005)$. iliş̧ki boyutu ise testin değerine bakılarak söylenmektedir (Cramer' $V=, 200)$. Bu sonuca göre de ders çalışma yaklaşımları ile akademik başarıları arasında orta düzeyde etkiye sahip yani orta düzeyde ilişki olduğu söylenebilir.

\section{Tartışma ve Sonuç}

Araştırma kapsamında öncelikle önlisans düzeyinde öğrencilerin ders çalışma yaklaşımları belirlenmiştir. Bu doğrultuda çalışmaya katılan öğrencilerin 304'ü (\%48.8), ders çalışma süreçlerinde derin yaklaşımı benimserken, 319'u $(\% 51,2)$ ise yüzeysel yaklaşımı tercih etmişlerdir. Bu sonuç, ortalama her iki öğrenciden birinin derin diğerinin yüzeysel yaklaşımı benimsediğini göstermektedir. Bu öğrencilerin bulunduğu sınıflara derse giren öğretmenlerin derin yaklaşımı benimseyen öğrencilerin bu yönelimlerini desteklemeleri ayrıca yüzeysel yaklaşımı benimseyen öğrenciler ile ilgili de yaklaşım değiştirme yönünde etkinlikler yapmaları gerekli görülmektedir. Çünkü yüzeysel yaklaşımı benimseyen öğrencilerin, derin öğrenme yaklaşımlarını benimsemeleri yapılacak eğitim etkinlikleri ile sağlanabilir. Bu alanda yapılan çalışmalarda da, öğrencilerin benimsediği ders çalışma yaklaşımının, konu, öğretmen davranışı, ders işleme yöntemlerine bağlı olarak değişebildiği ortaya konmuştur (Ramsden, 1991; Spencer, 2003). Bu sebeple eğitimcilerin öğrenmeöğretme ortamlarını planlarken, öğrencilerin ders çalışma süreçlerinde benimsedikleri yaklaşımları etkileyen faktörleri dikkate almaları, gelişmiş toplumların ihtiyaç duyduğu 
Mesut ÖZONUR | Halil KAMIŞLI

birey özelliklerini öğrencilerin kazanmaları adına önemli görülmektedir. Ayrıca literatürdeki araştırmalar konuya ilişkin ilgi ve görüşleri, konuya çalışma deneyimleri, konunun gerekliliğine inanmaları gibi faktörler ile öğrencilerin ders çalışma yaklaşımlarındaki farklılığı açıklamaktadır (Kember, Charlesworth, Davies, McKay ve Stott, 1997; MinasianBatmanian, Lingard ve Prosser, 2005; Zhang, 2000). Ancak Çuhadar, Gündüz ve Tanyeri (2013) çalışmalarında, ders çalışma yaklaşımları arasında herhangi bir fark olmadığı sonucunu da elde etmişlerdir.

Araştırmanın ikinci alt problemi çerçevesinde yapılan çalışmalarda, önlisans düzeyinde üniversite öğrencilerinin ders çalışma yaklaşımları ile akademik başarıları arasında bir ilişki aranmıştır. Derin ve yüzeysel yaklaşıma sahip öğrencilerin, akademik başarıları açısından fark olup olmadığını ortaya koymak için Ki-Kare testi yapılmıştır. Bu test sonucunda anlamlı bir fark bulunmuştur. Bu farkın yönü ve ilişki düzeyini belirlemek için Cramer's V testi yapılmış ve orta düzeyde anlamlı bir ilişki bulunmuştur. Yapılan bu işlemlerden sonra çıkan sonuç; ders çalışma yaklaşımlarının akademik başarıyı etkilediği, derin yaklaşımı benimseyen öğrencilerin yüzeysel yaklaşımı benimseyen öğrencilerden daha başarılı olduğudur. Bu alanda yapılan çalışmalar, araştırma sonuçları ile paralellik göstermekte olup, derin yaklaşım özellikleri gösteren öğrencilerin diğerlerine göre daha başarılı olduğu yönündedir (Booth, Luckett ve Mladenovic, 1999; Byrne, Flood ve Willis, 2002; Gow, Kember ve Cooper, 1994). Hatta Miškulin ve Vrdoljak (2017) yaptıkları çalışmada derin çalışma yaklaşımının akademik başarının pozitif yönde yordayıcısı olduğunu ifade etmişlerdir. Başka bir çalışma ise farklı ders başarı seviyelerindeki öğrencileri ayırt etmede derin ve yüzeysel yaklaşımlar kullanmanın etkinliğini göstermiştir (Bunce ve diğ., 2017). Derin yaklaşım özellikleri içerisinde, sorgulamayı, araştırmayı, günlük hayatla ilişkilendirip içselleştirmeyi barındırır. Yüzeysel yaklaşım ise konunun bütününden uzak, ezbere dayalı ve minumum ders geçmeye odaklı özellikler içerir. Dolayısı ile derin yaklaşımı benimseyen öğrencilerin daha etkili öğrenme süreçlerinden geçip istenilen düzeyde öğrenme sağlamaları beklenen bir durumdur. Araştırma sonuçları da bu durumu destekler niteliktedir. Araştırma sonuçları derin yaklaşımı benimseyen öğrencilerin, yüzeysel öğrencilere göre akademik açıdan daha başarılı olduğunu ortaya koymuştur. Ders çalışma yaklaşımı ile akademik başarı arasındaki bu ilişki istatistiksel olarak orta düzeyde bulunmuştur. Bunun sebebi olarak ise akademik başarıya etki eden tek faktörün ders çalışma yaklaşımı olmadığı ve daha birçok faktör olması olarak görülmektedir (zeka, öğrenme hızı vb. zihinsel faktörler, öz-yeterlik, benlik saygısı, kişilik yapısı, motivasyon ve ders çalışma alışkanlıkları, ailenin sosyo-ekonomik durumu, anne-baba tutumu, okul yöneticilerinin ve öğretmenlerin yeterliliği ve tutumu gibi) (Arıcı, 2007; Dağdelen, 2013; Özer ve Anıl, 2011; Polat, 2009; Şevik, 2014; Wang, 2004). Bu faktörlerin çokluğu ve çeşitliliği çıkan sonucu etkilemiştir.

Yapılan bu çalışmada meslek yüksekokulu öğrencilerinin ders çalışma yaklaşımları belirlenmiş ve akademik başarı ile ilişkisi ortaya konmuştur. Çıkan sonuç, ders çalışma süre- 
cinde derin yaklaşımı benimseyen öğrencilerin diğer öğrencilere göre akademik anlamda daha başarılı olduğudur. Fakat yüzeysel yaklaşımı benimseyen öğrencilerin, ders çalışma sürecindeki bu yaklaşımlarının, uygun yöntem, teknik ve iletişim şekilleri ile derin yaklaşım lehine değiştirilebildiği bilinmektedir. Öğretmenlerin bu gerçeğin farkında olmaları ve öğrenme sürecinde dikkate almaları çok önemli görülmektedir. Toplumun ve bireylerin daha fazla ilerlemesi için öğretmenlere, öğrencileri derin çalışma yaklaşımı kullanımı için motivasyonlarını attıracak şekilde teşvik etmeleri ve buna dayalı eğitim-öğretim planlamaları önerilmektedir. Bu doğrultuda, ders ve dönem başlarında öğrencilerin ders çalışma yaklaşımları belirlenebilir, yüzeysel yaklaşımı sergileyen öğrencilere yönelik eğitim etkinlikleri düzenlenebilir. Ayrıca öğrenmeyi ve akademik başarıyı etkileyen birçok faktör olduğu belirtilmişti. Bu çalışmada bu faktörlerden biri olan ders çalışma yaklaşımı üzerinde durulmuştur. Diğer faktörler ile ilgili de çalışmaların yapılması, istenilen düzeyde öğrenmenin gerçekleşmesi ve akademik başarının elde edilmesi adına çok önemli görülmektedir.

\section{Kaynaklar}

Alkan, C., Doğan, H., ve Sezgin, i. (1991). Mesleki ve Teknik Eğitimin Esasları. Ankara: Gazi Üniversitesi Teknik Eğitim Fakültesi Matbaası.

Arıcı, i. (2007). illköğretim din kültürü ve ahlak bilgisi dersinde öğrenci başarısını etkileyen faktörler (Ankara örneği). Yayımlanmamış doktora tezi, Ankara Üniversitesi, Ankara.

Beattie,V., Collins, B., \& Mclnnes, B. (1997). Deep and surface learning: A simple or simplistic dichotomy? Accounting Education, 6 (1).

Biggs, J. (1999). What the Student Does: Teaching for Enhanced Higher Education, 18(1).

Bonsaksen, T., Sadeghi, T., \& Thorrisen, M. M. (2017). Associations between self-esteem, general selfefficacy, and approaches to studying in occupational therapy students: A cross-sectional study. Occupational Therapy in Mental Health, 33(4), 326-341.

Booth, P., Luckett, P., \& Mladenovic, R. (1999). The quality of learning in accounting education: The impact of approaches to learning on academic performance. Accounting Education, 8 (4).

Bunce, D.M., Komperda, R., Schroeder, M.J., Dillner, D.K., Lin, S., Teichert, M.A. \& Hartman, J.R. (2017). Differential use of study approaches by students of different achievement levels. Journal of Chemical Education. 94, 1415 -1424.

Byrne, M., Flood, B., \& Willis, P. (2002). The relationship between learning approaches and learning outcomes: a study of Irish accounting students. Accounting Education, 11(1).

Çuhadar, C., Gündüz, Ş. ve Tanyeri, T. (2013). Bilgisayar ve Öğretim Teknolojileri Eğitimi Bölümü öğrencilerinin ders çalışma yaklaşımları ve akademik öz-yeterlik algıları arasındaki ilişkinin incelenmesi. Mersin Üniversitesi Eğitim Fakültesi Dergisi, 9(1), 251-259. 
Mesut ÖZONUR | Halil KAMIŞLI

Dağdelen, S. (2013). Biyoloji derslerinde öğretmenlerin kişilerarası davranışı, sını öğrenme ortamı ve öğrenci başarısı arasındaki ilişkinin incelenmesi. Yayınlanmamış yüksek lisans tezi, Marmara Üniversitesi, İ̇tanbul.

Demircioğlu Memiş, A. (2007). Öğrencilerin çalışma oryantasyonlarını etkileyen demografik faktörler. Türk Eğitim Bilimleri Dergisi, 5 (2).

Entwistle, N. (2000). Promoting deep learning through teaching and assessment: Conceptual frameworks and educational contexts. Teaching and Learning Research Programme (TLRP)

Entwistle, N., \& McCune, V. (2004). The Conceptual Bases of Study Strategy Inventories. Educational Psychology Review, 16 (4).

Gow, L., Kember, D., \& Cooper, B. (1994). The teaching context and approaches to study of accountancy students. Issues in Accounting Education, 9 (1).

Hassanbeigi, A., Askari, J., Nakhjavani, M., Shirkhoda, S., Barzegar, K., Mozayyan, M.R., \& Fallahzadeh, H. (2011). The relationship between study skills and academic performance of university students.Procedia-Social and Behavioral Sciences, 30, 1416-1424.

Houghton, W. (2004). Engineering Subject Centre Guide: Learning and Teaching Theory for Engineering Academics. Loughborough: HEA Engineering Subject Centre.

Howie, S.J., \& Pietersen, J.J. (2001). Mathematics literacy of final year students: South African realities. Studies in Educational Evaluation, 7 (25).

Jansen, E.P.W.A., \& Suhre, C.J.M. (2010). The effect of secondary school study skills preparation on firstyear university achievement. Educational Studies, 36(5), 569-580.

Kember, D., Charlesworth, M., Davies, H., Mckay, J., \& Stott, V. (1997). Evaluating the effectiveness of educational innovations: Using the study process questionnaire to show that meaningful learning occurs. Studies in Educational Evaluation,23(2), 141-157.

Minasian-Batmaniani L.C., Lingard, J., \& Prosser, M. (2005). Differences in students' perceptions of learning compulsory foundation biochemistry in the health sciences professions. Advances in Health Sciences Education,10, 279-290.

Miškulin, N. \& Vrdoljak, G. (2017). Predicting academic achievement based on goal orientations and study approaches. Croatian Journal of Education, 19(3), 919-946.

Özer, Y., ve Anıl, D. (2011). Öğrencilerin fen ve matematik başarılarını etkileyen faktörlerin yapısal eşitlik modeli ile incelenmesi. Hacettepe Üniversitesi Eğitim Fakültesi Dergisi, 41.

Patterson, M., Perry, E., Decker, C., Eckert, R., Klaus, S., \& Wendling, L. (2003). Factors Associated With High School mathematics performance in the United States. Studies in Educational Evaluation, 29. 
Polat, S. (2009). Akademik başarısızlığın toplumsal eşitsizlik temelinde çözümlenmesi. Eğitim Bilim Toplum Dergisi, 7 (25).

Purdue, N., \& Hattie, J. (1999). The relationship between study skills and learning outcomes: A meta-analysis. Australian Journal of Education, 43 (1).

Ramsden, P. (1991). Learning to Teach in Higher Education. London: Routledge Falmer.

Rostaminezhad, M.A., Porshafei, H. \& Ahamdi, A.A. (2019). Can effective study approaches mediate the negative effect of social networking on academic performance? Educ Inf Technol, 24, 205-217.

Sarıer, Y. (2016). Türkiye'de Öğrencilerin Akademik Başarısını Etkileyen Faktörler: Bir Meta-analiz Çalışması. Hacettepe Üniversitesi Eğitim Fakültesi Dergisi. 1300 (5340).

Spencer, K. (2003). Approaches to Learning and Contemporary Accounting Education. Education in a Changing Environment Conference Proceedings.

Şevik, Y. (2014). ilköğretim müdür ve müdür yardımcılarının öğrencilerin akademik başarısını etkileyen faktörlere ilişkin görüşleri ile akademik başarısına katkıları. Yayınlanmamış yüksek lisans tezi, Mehmet Akif Üniversitesi, Burdur.

Wagner, P., Schober, B., \& Spiel, C. (2008). Time investment and time management: An analysis of time students spend working at home for school. Educational Research and Evaluation, 14 (2).

Wang, D. B. (2004). Family background factors and mathematics success: A comparison of Chinese and US students. International Journal of Educational Research, 41.

West, C., \& Sadoski, M. (2011). Do study strategies predict academic performance in medical school? Medical Education, 45(7), 696-703.

Yılmaz, B., M. ve Orhan, F. (2011) Ders Çalışma Yaklaşımı Ölçeği'nin Türkçe Formunun Geçerlik ve Güvenirlik Çalışması, Eğitim ve Bilim 36(159).

Zhang, L. (2000). University students' learning approaches in three cultures: An investigation of Biggs's 3P model. The Journal of Psychology, 134(1), 37-55. 